\title{
Description and Modeling of the Additive Manufacturing Technology for Aerodynamic Coefficients Measurement
}

\author{
Saeed Daneshmand1, ${ }^{*}$ - Cyrus Aghanajafi² \\ ${ }^{1}$ Department of Mechanical and Aerospace Engineering, Science and Research Branch, Islamic Azad University, Tehran, Iran; \\ 2 K. N. Toosi University of Technology, Iran
}

\begin{abstract}
Casting, machining and additive manufacturing technologies are used in order to produce wind tunnel testing models. The models can also be analyzed by computational fluid dynamics methods. Both have their advantages and disadvantages. Since several wind tunnel models are required to accomplish aerodynamic experiments, nowadays, one of the best methods for models and airfoils manufacturing are additive manufacturing technologies. These methods are increasingly used in aerospace industry. In this research, wing and tail of a wind tunnel test model which has complicated sections, are produced by fused deposition modeling technology. In order to improve mechanical properties and surface roughness an electroplating is used on the surface of a RP model. Metal models along with fused deposition modeling models and electroplating models were tested in wind tunnels with different angels of attack. Results indicated that aerodynamic coefficients of electroplating model with a chromium coating was closer to metal model than those of AM model without electroplating. Substituting conventionally made parts with electroplating models, saves both cost and time. These models can be used in wind tunnel tests and aerodynamic data have acceptable quality.
\end{abstract}

Keywords: additive manufacturing, wind tunnel, angels of attack, aerodynamic coefficient

\section{O INTRODUCTION}

In order to reduce the product development time and the cost of tooling, layered manufacturing techniques were developed commonly known as additive manufacturing (AM) technologies. This technology encompasses a group of manufacturing techniques, in which adding the material layer-by-layer generates the shape of the physical part. Layer manufacturing, rapid prototyping, solid free form fabrication, additive manufacturing, digital manufacturing are all the names of the processes that are capable of producing three-dimensional (3D) parts from computer aided design (CAD) data directly. The first purpose of this technology was to produce prototypes quickly in an additive manner by adding layer upon layer [1] and [2].Researchers and applicants have started to apply the new AM technologies to different areas and domains like making tools and dies which is known as rapid tooling, and manufacturing of end use products with low volume quantity, which is known as rapid manufacturing. Wind tunnel testing is an integral part of the design process in many industries. Whether an object is stationary or mobile, wind tunnels provide insight into the effects of air as it moves over or around the test model. Since the physics of flight depend on the proper flow of air to produce lift and reduce drag, wind tunnel evaluations are essential in the aerospace industry. Even in an age of advanced computer simulation, aerospace engineers still rely on the testing of physical models to verify the computer data and establish baseline aerodynamic information. In the never-ending quest for more efficient automobiles, aerodynamics plays a very important part in vehicle design. To make the models for the wind tunnel, automotive and aerospace companies have relied on traditional manufacturing operations. They have used milling, turning and fabrication to convert metal and plastic into test models. These operations require programming, set up and operator supervision, which adds to lead time and cost. Considering the amount of material that ends up as chips on the floor, the material costs can be high. Additive manufacturing improves the lead time and cost of the test part for the wind tunnel testing. Due to the high costs of building a model, program managers often rely heavily on analytical tools, such as computational fluid dynamics (CFD), to predict how a missile system might perform. CFD is used extensively in the aerospace field to provide designers and engineers further insight into design issues that may arise at various stages in the design process. In addition, CFD can be used to provide useful information on preexisting designs such as homebuilt aircraft. In aerospace applications, CFD can be used as the sole means of analysis, or to complement additional analysis techniques and processes. Although CFD can provide valuable data, it typically requires more time to produce final results and has limitations providing data over a full range of flight conditions. A combination of testing and CFD can be used to acquire a more complete data set. A number of research works related to the making of wind tunnel models by additive manufacturing which can be produced, have been published in the past years. Landrum et al. [3] tested airfoil models in a subsonic wind tunnel: a conventional cast polyurethane model and two photopolymer models made by stereolithography. They reported 
comparable dimensional tolerances and fabrication times for the rapid prototyping (RP) and conventional models, with the biggest difference being in the drag coefficient for both the RP models, which was about half the value measured for the cast model. They attributed this result to the rougher surface of the RP models inhibiting the formation of laminar separation bubbles. Aghanajafi et al. [4] described the effects of layer-thickness models on aerodynamic coefficients to construct wind-tunnel-testing models produced with rapid prototyping. These models were fabricated from SOMOS NanoTool by stereolithography. Results from this study show that layer thickness does have an effect on aerodynamic characteristics. Springer et al. [5] evaluated aerodynamic characteristics of wind-tunnel models produced by rapid prototyping methods. They concluded from this study that, preliminary design studies and limited configurations could be used due to the RP material properties that allowed bending of model components under high loading conditions. Hildebrand et al. [6] and Tyler et al. [7] described two wind tunnel models and investigated issues such as the integration of pressure taps, model sagging under load. They found that it was necessary to stiffen the plastic model to prevent excessive wing deflection. Nadooshan et al. [8] tested a polycarbonate model made by FDM against a conventional machined steel model. The results were a generally good agreement between the metal and plastic models up to about 10 degrees of angle of attack, when the plastic model's deflection under the higher loading produced more noticeable differences. Daneshmand et al. [9] described two wind tunnel models; these models were rocket configuration constructed using CK45 and $\mathrm{ABSi}$ material for wind tunnel testing. Results from this study show good agreement between the two models and increased use of RP components in wind tunnel models could reduce the time wind tunnel model fabrication. Surface roughness is an important parameter in wind tunnel testing models fabrication [10]. The purpose of this work is to demonstrate how additive manufacturing with electroplating coating can be effectively applied to fabricate test models used in aerodynamic experimental investigations. Three models are prepared and produced at various conditions for testing in wind tunnel and determining the aerodynamics coefficients. AM models constructed using FDM with ABS-M30 as a material and FDM model with chromium coating. AISI 1045H (CK45) was chosen as the material for the machined metal model. The roughness for each model was $16 R_{a}, 0.832 R_{a}$ and $0.410 \mu \mathrm{m} R_{a}$. Wind tunnel is an intermittent blow down tunnel, which operates by high-pressure air flowing from storage to either vacuum or atmosphere conditions. Testing was done over the Mach range of 0.1 to 0.3 . All models were tested at angle-of-attack (AOA) ranges from -2 degrees to +14 degrees at zero sideslip. Coefficients of normal force, axial force, pitching moment, and lift over drag are shown at each of these Mach numbers.

\section{ADDITIVE MANUFACTURING TECHNOLOGIES AND FDM PROCESS}

The term additive manufacturing (AM) is used in a variety of industries to describe a process for rapidly creating a system or part representation before final release or commercialization. In other words the emphasis is on creating something quickly and that the output is a prototype or basis model from which further models and eventually the final product will be derived. AM technology certainly significantly simplifies the process of producing complex threedimensional objects directly from computer aided design data. Additive manufacturing technologies can be classified in three categories according to the initial state of the raw material used (liquid, powder, and solid). Regardless of the material state, all AM techniques use the following five main steps to produce prototypes, patterns or final parts: CAD model preparation, STL translation, slicing and production of technological program, additive manufacturing, and finally, post processing of the prototype. Performance measures of $\mathrm{AM}$ techniques such as dimensional accuracy, surface roughness, mechanical strength, build time, as well as material properties and post processing, define the final use of the corresponding prototype. The most common technologies used are Stereolithography (SL), Selective Laser Sintering (SLS), Fused Deposition Modeling (FDM), and 3D Printing (3DP). Each of these technologies has strengths and weaknesses with some of these technologies suitable for some application and some not [11] and [12]. Also, it is very advantageous to present a design in client presentations; consumer evaluations, bid proposals, and regulation certification. The models produced by three dimensional printing (3DP) are not so accurate when compared to other rapid prototyping technologies [13]. Over the past few years, improvements in equipment, materials, and processes have enabled significant improvements in the accuracy of Fused Deposition Modeling technology. FDM process creates parts by extruding material through a nozzle that traverses in $\mathrm{X}$ and $\mathrm{Y}$ to create each two-dimensional layer. The use of a nozzle with a diameter of typically $0.3 \mathrm{~mm}$ limits 
resolution an accuracy also the need for the nozzles to physically traverse the build area limits build speed, but the process is very easy to set up and can operate in an office or factory environment. Support removal can be manual or, when water soluble supports are employed, they may simply be dissolved with the latter approach being most valuable with more complicated geometries. Fig. 1 shows a schematic of the FDM process that can produce parts in material including polycarbonate, polyphenylsulfone and, most commonly acrylonitrate butadiene styrene (ABS). The simplicity of the process should make it suitable for the development of a wide variety of thermoplastic polymers, which may open up opportunities for rapid manufacturing [14].

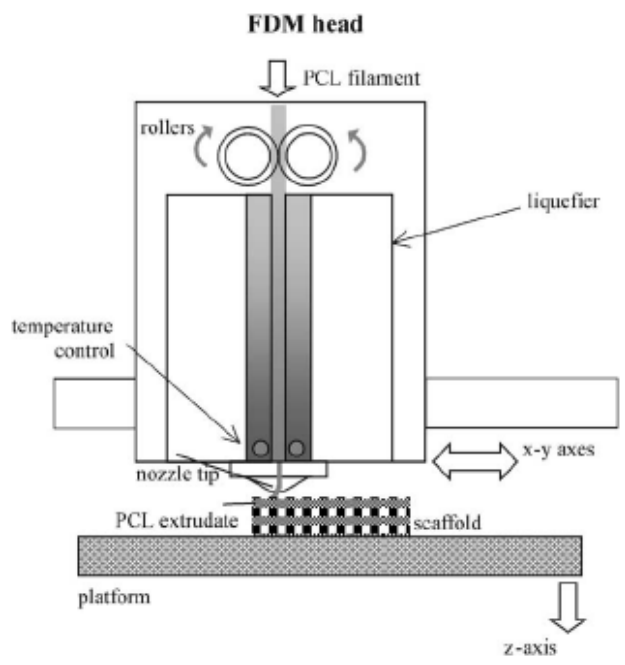

Fig. 1. Schematic diagram of FDM process [15]

\section{CHROMIUM COATING}

In recent years, the AM models have found increased uses in wind tunnel. Coating AM parts with metals was shown to be a promising route for the fabrication of wind tunnel models. Electroplating deposits a thin layer of metal on the surface of a part using the FDM process. This metal coating can be both decorative and functional. The coating gives the appearance of production metal or plated parts and provides a hard, wear-resistant surface with reflective properties. The electroplated part also has improved mechanical properties. With simple finishing techniques, FDM parts are ready for electroplating with alloys such as chromium, nickel, copper, silver and gold. Combining the properties of materials with those of a metal coating, the part has strength, durability and heat resistance that is ideal for functional applications. ABS plastic, the material that FDM models are made from, works very well with this process. The model is chemically etched, which removes the butadiene molecules from the surface and improves bonding of the subsequent layers. Once etched, the part is then coated with a layer of palladium, which acts as an intermediate bonding agent, followed by a layer of chromium to provide the necessary conductivity. At this point, the model is placed in a tank containing a solution of the metal to be deposited and given a negative electric charge, which attracts the positively charged metal ions from the solution and becomes a solid metal again. Hard chrome electroplating gives the plastic model a very durable coating, but it can have a tendency to make the part somewhat brittle.

\section{MATERIAL SELECTION}

Fused deposition modeling offers a unique variety of thermoplastic modeling materials for FDM systems. The mechanical properties of ABS-M30, polycarbonate (PC), PC-ABS and polyphenolsulfone (PPSF) can withstand the forces and stresses induced as the air flow strikes the model's surface. Each FDM material can be used for wind tunnel models. Selection will be based on the strength needed to resist the wind forces in the tunnel. The material options currently include ABS, a high-impact grade of ABSi, investment casting wax, and elastomer. The use of ABS provides the impact resistance, toughness, heat stability, chemical resistance, and the ability to perform functional tests on sample parts [16]. ABS-M30 is up to 25 to $70 \%$ stronger than standard ABS and is an ideal material for conceptual modeling, functional prototyping, manufacturing tools, and enduse-parts. ABS-M30 has greater tensile, impact, and flexural strength than standard ABS. Layer bonding is significantly stronger than that of standard ABS, for a more durable part. In this research AM models were constructed using the ABS-M30 materials. ABS-M30 gives real parts that are stronger, smoother, and with better feature detail. Steel (AISI 1045H) was chosen as the material for the machined metal model. Material properties of ABS-M30 are shown in Tables 1 and 2.

Table 1. Material properties of ABS-M30

\begin{tabular}{ccc}
\hline Mechanical properties & Test Method ASTM & Metric \\
\hline Tensile strength & D638 & $36 \mathrm{MPa}$ \\
Tensile modulus & D638 & $2,413 \mathrm{MPa}$ \\
Tensile elongation & D638 & $4 \%$ \\
Flexural stress & D790 & $61 \mathrm{MPa}$ \\
Flexural modulus & D790 & $2,317 \mathrm{MPa}$ \\
Flexural elongation & D790 & $52 \%$ \\
\hline
\end{tabular}


Table 2. Thermal properties of ABS-M30

\begin{tabular}{lcc}
\hline \multicolumn{1}{c}{ Thermal properties } & Test method & Metric \\
\hline Heat deflection & ASTM D648 & $96{ }^{\circ} \mathrm{C}$ \\
Vicat softening temp. & ASTM D1525 & $99^{\circ} \mathrm{C}$ \\
Coefficient of thermal expansion & ASTM E831 & $8.82 \mathrm{E}-05 \mathrm{~mm} /{ }^{\circ} \mathrm{C}$ \\
Coefficient of thermal expansion & ASTM E831 & $8.46 \mathrm{E}-05 \mathrm{~mm} /{ }^{\circ} \mathrm{C}$ \\
Glass transition & DSC (SSYS) & $108^{\circ} \mathrm{C}$ \\
\hline
\end{tabular}

\section{SURFACE ROUGHNESS}

Additive manufacturing is a manufacturing technology that fabricates 3D physical models using a layered manufacturing process that stacks and bonds thin layers in one direction. In comparison with the previous numerically controlled (NC) manufacturing technology, AM can rapidly fabricate high level models with complex shapes without geometric restriction under more comfortable working conditions. FDM technology is fundamentally based on surface chemistry, thermal energy, and a layer manufacturing process [17]. As the AM process is performed using layered manufacturing, the surface roughness of the FDM part is excessively rough, as shown in Figs. 2 and 3 . When testing at very high wind speeds, it is true that surfaces must be very smooth. However, at lower speeds, companies are using FDM models directly from the system. For those instances where parts must be finished before going into the wind tunnel, there are options. Although FDM materials are durable and somewhat abrasion resistant, and therefore somewhat resistant to sanding, there are a number of finishing techniques that are simple and fast. Once the perceived limitation of surface roughness is set aside, companies in industries that range from aerospace to architecture can leverage the strength, detail and accuracy of FDM for wind tunnel models. In doing so, they will reduce cost, time and effort. As noted previously, companies are using FDM models that go directly from the system to the wind tunnel. For many applications, surface roughness will not be an issue until tunnel speeds reach elevated levels, when the part is oriented properly. However, when surface roughness is imperative, there is a fast and efficient smoothing process. The surface roughness of the parts is not satisfactory for general engineering purposes. For this reason, surface roughness is a key issue in AM. The application of surface roughness had effect on the aerodynamic characteristics. The surface roughness for FDM model and model with electroplating coating was $16\left(R_{a}\right)$ and $0.832 \mu \mathrm{m}\left(R_{a}\right)$, which is determined by the following trigonometric equation:

$$
R_{a}=\alpha \sin \frac{\theta}{4} \tan \theta
$$

where $R_{a}$ is the arithmetic average surface roughness, $\alpha$ the layer thickness and $\theta$ is the angle between the surface normal and the vertical direction [18].

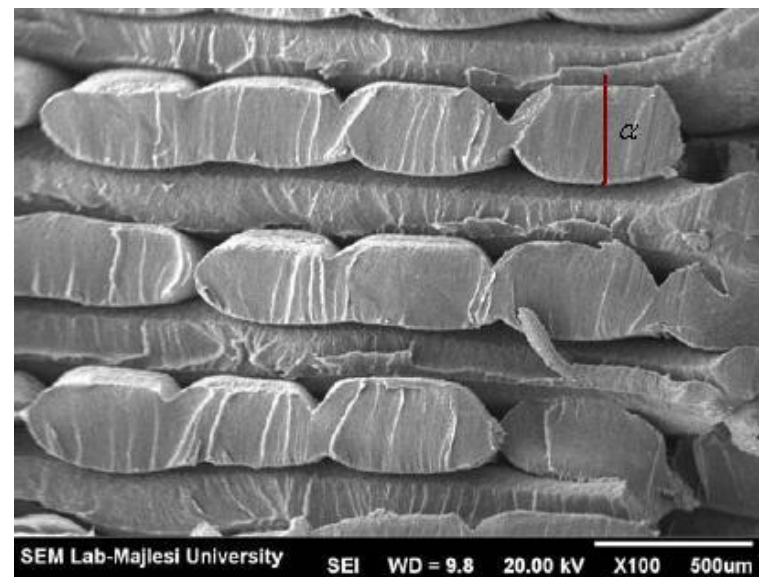

Fig. 2. Cut surface of ABS-M3O fabricated using FDM observed under SEM

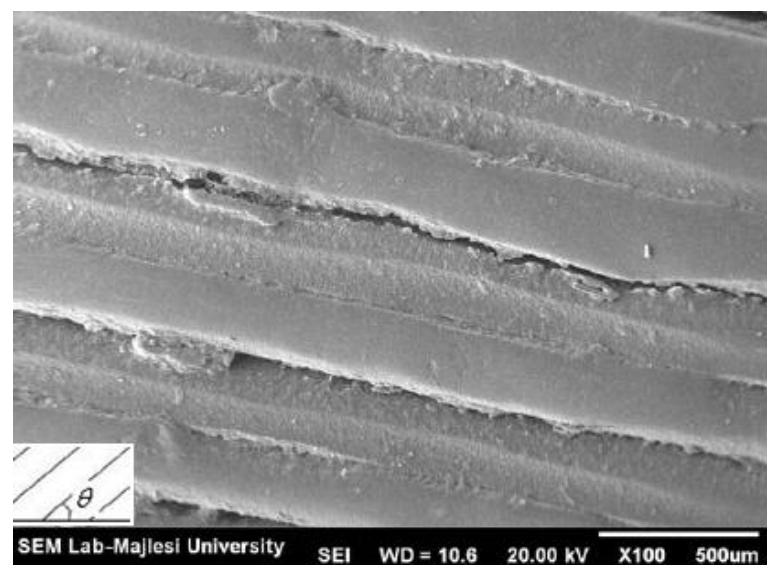

Fig. 3. Side-view of ABS-M3O fabricated using FDM observed under SEM

\section{DESIGN OF TESTING MODELS}

Some parts of the models which had complicated sections and were very difficult to be produced by traditional methods, were manufactured by FDM method (Fig. 4). The dimensions for the scaled model of the missile are $52 \times 8 \times 8 \mathrm{~cm}$. The model was built in several pieces and then assembled. Three models were fabricated. The first model was constructed using steel in three parts, a nose, body and tail as shown in Fig. 5. The second model was manufactured using FDM nose and FDM tail attached to cylindrical steel as depicted in Fig. 6. As for the third model, nose and tail were produced using FDM and the roughness of the surface 
was improved by implementing a chromium coating. This model is shown in Fig. 7. The cylindrical steel provides strength and rigidity to the plastic model and also allows larger scale models to be built. The cylindrical steel, fabricated from AISI 1045H (CK45), is a $30 \mathrm{~cm}$ long cylinder with a $8 \mathrm{~cm}$ outer diameter and a $7 \mathrm{~cm}$ inner diameter. The surface of the cylinder has a surface finish of a $0.410 \mu \mathrm{m}\left(R_{a}\right)$.

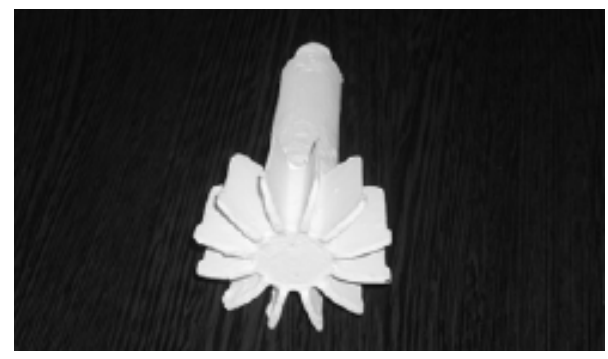

Fig. 4. Tail model configuration

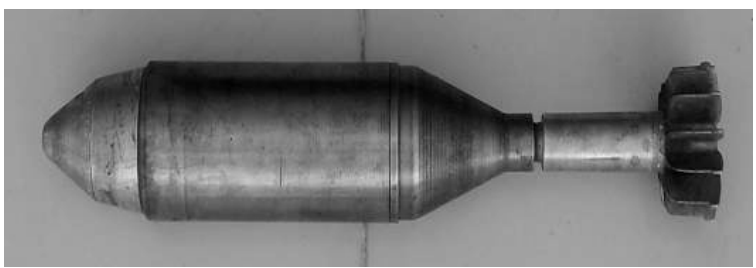

Fig. 5. Steel model configurations

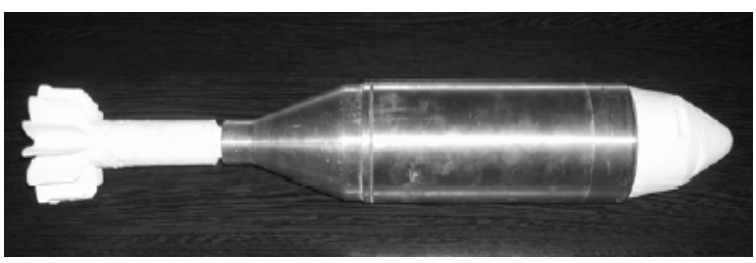

Fig. 6. Steel model with tail and nose FDM

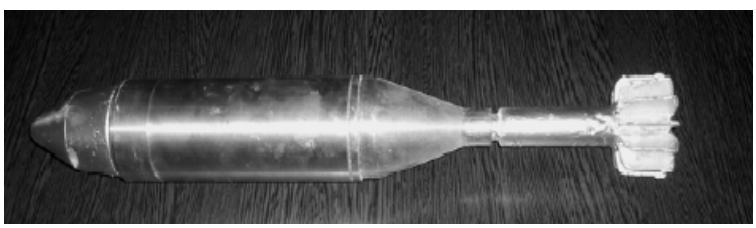

Fig. 7. Steel model with tail and nose FDM and Chromium coating

The inside forward end of the cylindrical steel was machined to a $6 \mathrm{~cm}$ diameter and threaded for attachment of the FDM nose. The FDM nose and tail was manufactured using a ABS-M30 and layer thickness was $0.180 \mathrm{~mm}$. The FDM parts were designed with the solid geometry models that were created using CATIA software and output as a 'stl' file. The surface roughness for FDM model, FDM model with electroplating coating and steel model was $16,0.832$ and $0.410 \mu \mathrm{m}\left(R_{a}\right)$ that is determined by perthometer M1 from Mahr company and trigonometrically derived mentioned equation.

\section{WIND TUNNEL}

The wind tunnel test was conducted in an openreturn low speed wind tunnel. The wind tunnel, made of Plexiglas walls, has working dimensions of $0.6 \times 0.6 \times 1 \mathrm{~m}$, and allows a maximum velocity of $150 \mathrm{~m} / \mathrm{s}$. Test section provides a Mach number range from 0.1 to 0.5 . Downstream of the test section is a hydraulically controlled pitch sector that provides the capability of testing angles-of-attack ranging from -5 to +25 degrees during each run. The wind tunnel is an intermittent blow down tunnel, which operates by high-pressure air flowing from storage to atmosphere conditions. The air then passes through the test section which contains the nozzle blocks and test region. The diffuser section has movable floor and ceiling panels, which are the primary means of controlling. A sixhole probe or a wake rake can be used to determine the wake characteristics of a test subject. Pilot probes are used to measure velocity gradients and to calculate drag through integration. Pressure ports can be used on a test subject to determine the forces on specific parts of a model or how forces are distributed across a model. Also, a boundary layer mouse can be employed to determine the boundary layer characteristics. Long force and moment data refers to the three forces (lift and drag) and three moments (roll, pitch, and yaw moment) that the wind applies to the test subject. Lift and drag forces were measured at various angles of attack (AOA) and downstream velocities, by means of a load cell and a Pitot tube. Measurements in the wind tunnel were carried out at the free-stream velocity varying from 34 to $150 \mathrm{~m} / \mathrm{s}$. The wind tunnel displays its measurements in electrical units, volts, and must be converted to forces using formulas found using derivations. Using these formulas:

$$
\begin{aligned}
& \text { Force }_{N}=\frac{\text { velocity }_{N \text { Air On }} \text {-velocity }}{N \text { Air Off }} \text {, } \\
& \text { Force }_{A}=\frac{\text { velocity }_{A \text { Air On }}-\text { velocity }_{A \text { Air Off }}}{\text { sensitivity }_{A}}+ \\
& +\frac{\text { velocity }_{N \text { Air On }}}{\text { Cross over } N A} \text {. }
\end{aligned}
$$

After finding the lift and the drag, it was necessary to also find the lift and drag coefficients and the ratio between them using these equations: 


$$
\begin{gathered}
F_{L}(\text { Lift })=F_{N} \cos (A O A)-F_{A} \sin (A O A), \\
F_{D}(\text { Drag })=F_{A} \cos (A O A)+F_{N} \sin (A O A),
\end{gathered}
$$

where $F_{N}$ is the force in the $x$-direction and $F_{A}$ is the force in the $y$-direction.

$$
\begin{aligned}
& C_{L}=\frac{F_{L}}{0.5 \cdot \rho \cdot v^{2} \cdot S}, \\
& C_{D}=\frac{F_{D}}{0.5 \cdot \rho \cdot v^{2} \cdot S},
\end{aligned}
$$

where $F_{L}$ is the measured lift, $\rho=1.225 \mathrm{~kg} / \mathrm{m}^{3}$, $S$ is the wing area, $v$ is the air speed, and $F_{D}$ is the measured drag. The aerodynamic loads are presented in a non-dimensional form. In the case of the force coefficients where $F$ is either lift, drag, or slid force the corresponding coefficient will have the form:

$$
C_{F}=\frac{F}{0.5 \rho \cdot v^{2} \cdot S}
$$

thus:

$$
C_{A}=\frac{A_{F}}{0.5 \rho \cdot v^{2} \cdot S} \quad \text { and } \quad C_{N}=\frac{N_{F}}{0.5 \rho \cdot v^{2} \cdot S} .
$$

Here, $C_{A}$ and $C_{N}$ are axial force coefficient and normal force coefficient, respectively. Similarly, the non-dimensional pitching moment coefficient becomes:

$$
C_{M}=\frac{M}{q \cdot S \cdot c}
$$

where $s$ is the pitching moment, $q$ is the dynamic pressure, $S$ is the planform area, and $c$ is the length of the chord of the airfoil.

\section{AERODYNAMIC AXIS SYSTEM AND ACCURACY}

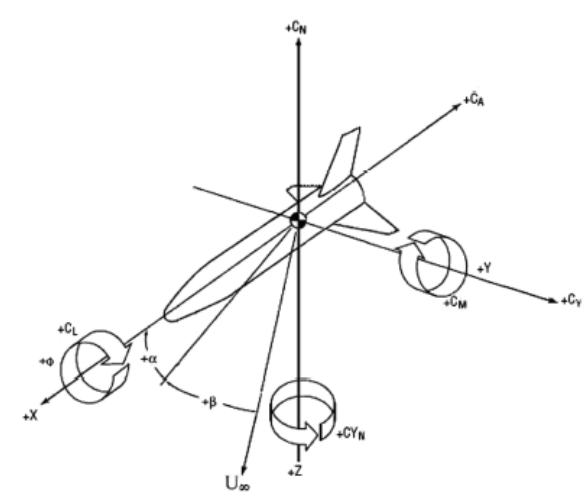

Fig. 8. Reference aerodynamic axis system

A wind tunnel test operating over Mach numbers ranging from 0.1 to 0.5 was undertaken to determine the aerodynamic characteristics of the models at 3 selected numbers for the precursor study. These Mach numbers were $0.1,0.2,0.3$ and the models were tested at the angle-of-attack ranges from -2 to $+14^{\circ}$ at zero sideslip. The reference aerodynamic axis system and reference parameters for the precursor study are shown in Fig. 8 [19] and [20]. Coefficients of pitching moment; normal force, axial force, and lift over drag are shown at each of these Mach numbers. The data accuracy resulting from the test can be divided into source of error in model dimensions and surface roughness.

\section{RESULTS}

Figs. 9 to 11 show the variation of the normal force coefficient via the angle of attack, for both FDM and steel testing models with respect to several typical Mach numbers. It is clear to see that the variation is almost linear and the normal force coefficient of the steel model is slightly greater than that of the FDM with chromium coating model when the angles of attack are positive. Figs. 12 to 14 show the variation of the axial force coefficient via the angle of attack changes, for both FDM and steel models with respect to several typical Mach numbers. It can be seen that the axial force coefficient of the steel model and FDM with chromium coating model is smaller than that of the FDM model for all angles of attack tested. To evaluate the aerodynamic coefficients of the models, the variation of the ratio $\mathrm{L} / \mathrm{D}$ with respect to several typical angles of attack is shown in Figs. 15 to 17 . It is seen that the ratio for the steel model is slightly greater than that for the FDM with chromium coating model at the same angle of attack. Furthermore, all ratios of the FDM model are lower than of the FDM with chromium coating model at any given angle of attack. It is thereby concluded that the FDM with chromium coating model exhibits better lift capability than the FDM model in the wind tunnel test. The study showed that between Mach numbers of 0.1 to 0.3 , the longitudinal aerodynamic data showed very good agreement between the steel model and FDM model with chromium coating (Figs. 9 to 20). The greatest difference in the aerodynamic data between the models at Mach numbers of 0.1 to 0.3 was in total axial force. The total axial force was slightly higher for the FDM model than the other models (Figs. 12, to 14). All the models showed good agreement in pitching moment (Figs. 18 to 20). In general, it can be said that FDM model with chromium coating longitudinal aerodynamic data showed a slight divergence at higher angles-of attack when compared to the metal model data. 


\section{CONCLUSIONS}

Recently, new systems and processes of additive manufacturing (AM) technologies have evolved. The suitability of the $A M$ techniques to the required application is a question that needs to be answered. This paper presents the development of an additive manufacturing technology based on aerodynamic analysis in the wind tunnel tests. $A M$ methods have

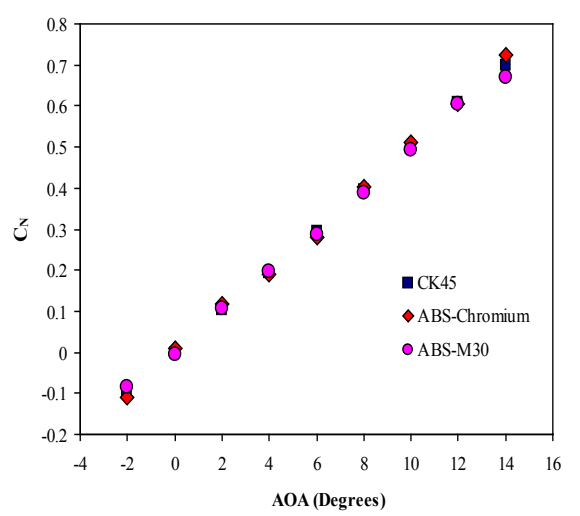

Fig. 9. Comparison of normal force coefficient at Mach 0.1

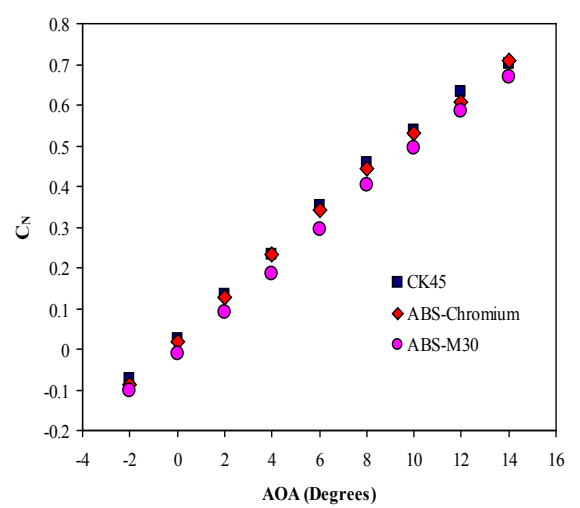

Fig. 10. Comparison of normal force coefficient at Mach 0.2

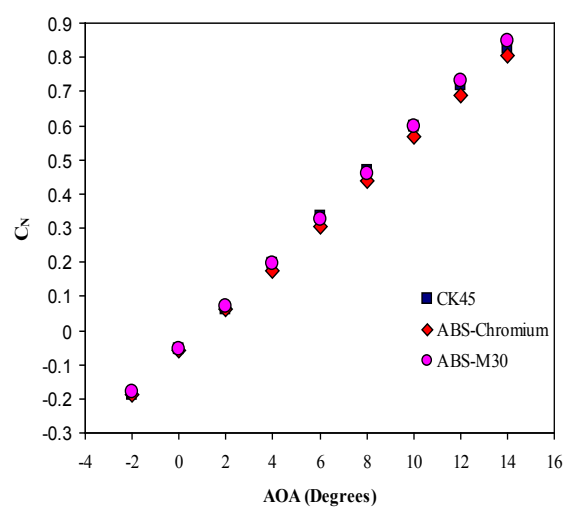

Fig. 11. Comparison of normal force coefficient at Mach 0.3 been considered as a potential source of improvement for conventional wind-tunnel models. Three models are analyzed and compared in wind tunnel tests. It has been concluded from this research that, since manufacturing complicated sections and airfoils is time-consuming and costly by machining and traditional methods, and also several models may be needed in wind tunnel tests additive manufacturing methods would be used in order to decrease the

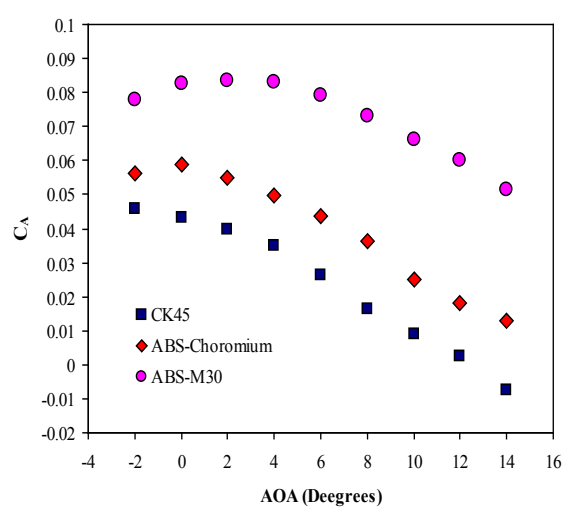

Fig. 12. Comparison of total axial force coefficient at Mach 0.1

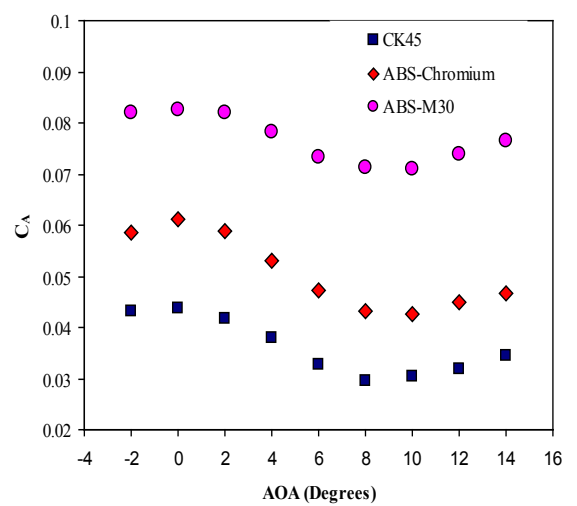

Fig. 13. Comparison of total axial force coefficient at Mach 0.2

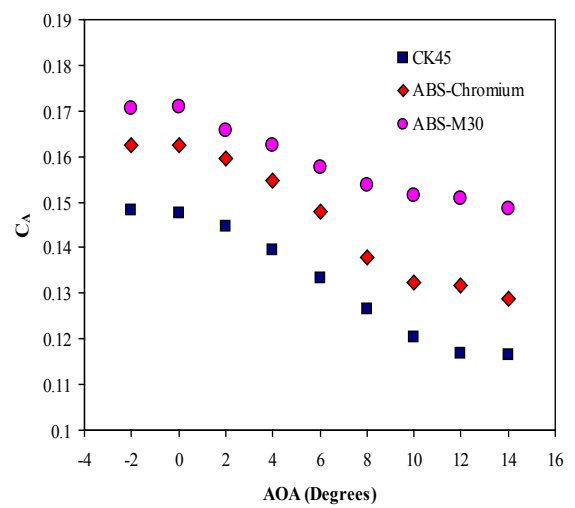

Fig. 14. Comparison of total axial force coefficient at Mach 0.3 
cost and the time of manufacturing. Regarding the accuracy necessary in aerodynamic tests AM models or AM models with chromium coating can be utilized. Generally, the difference between aerodynamic coefficients of metal models and AM models is due to the surface roughness and generated dimension tolerance. The aerodynamic data shows some small discrepancies between the three model types. In these graphs it can be seen that AM nose

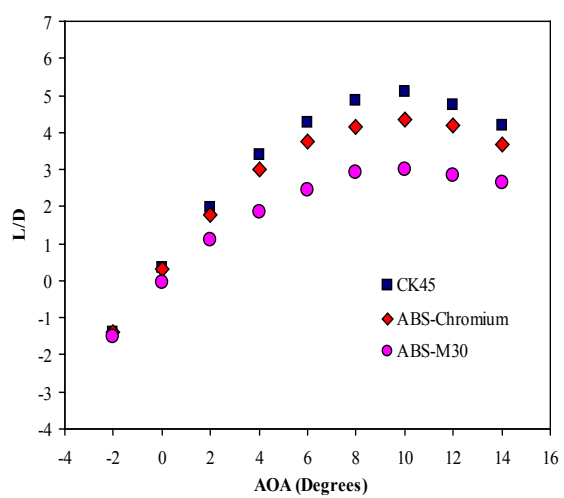

Fig. 15. Comparison of lift over drag at Mach 0.1

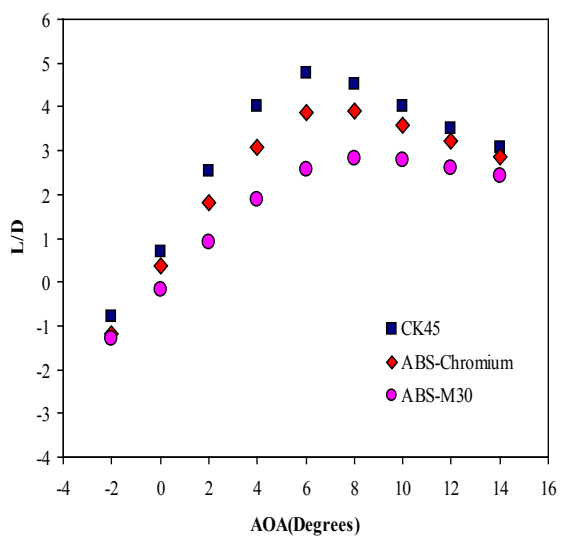

Fig. 16. Comparison of lift over drag at Mach 0.2

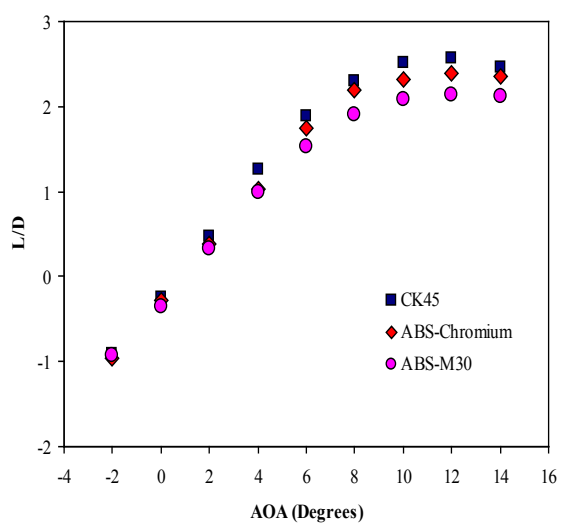

Fig. 17. Comparison of lift over drag at Mach 0.3 has an effect on the aerodynamic characteristics up to high speeds where the effect is less drastic than at lower Mach numbers. Using metal coating on AM models improved mechanical properties and surface roughness; accordingly aerodynamic coefficients are corrected regarding to AM models without coating and the results come closer to those of the real models or machined models. The use of AM models will provide a rapid capability in the determination

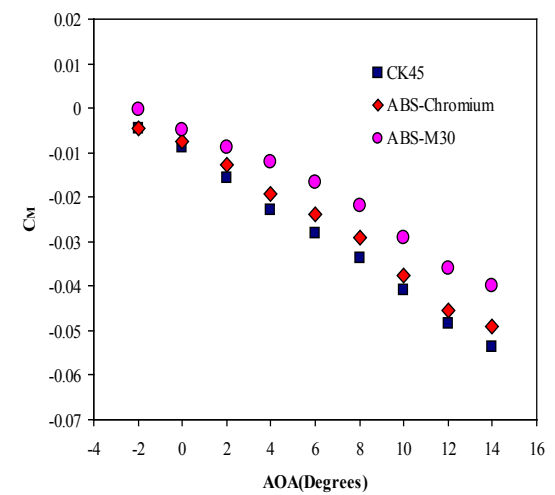

Fig. 18. Comparison of pitching moment coefficient at Mach 0.1

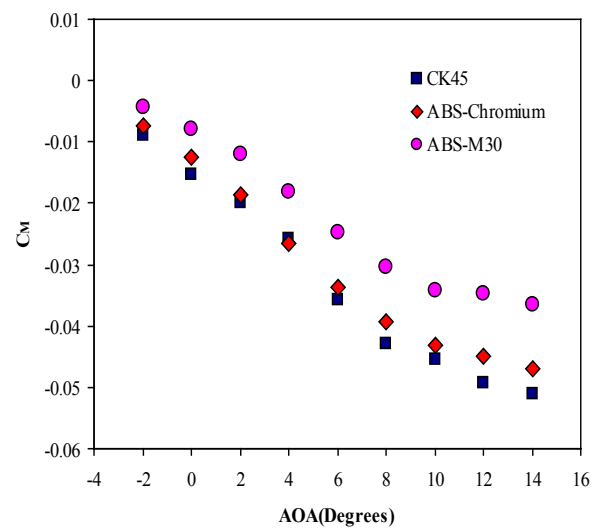

Fig. 19. Comparison of pitching moment coefficient at Mach 0.2

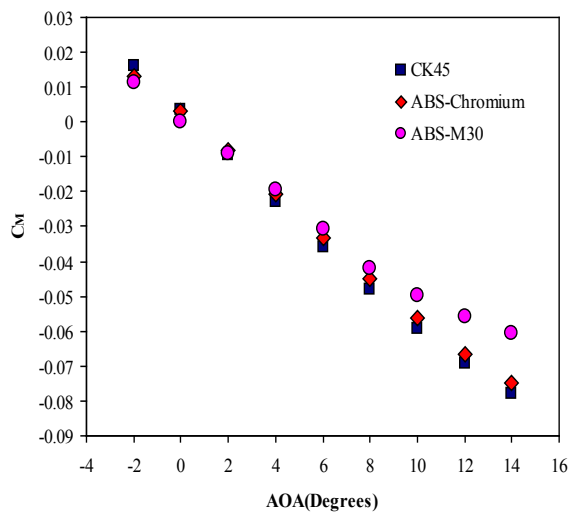

Fig. 20. Comparison of pitching moment coefficient at Mach 0.3 
of the aerodynamic characteristics of designs over a large Mach range. The fabrication processes of the prototype were also introduced and AM models with chromium coating were chosen due to their better aerodynamic analysis in the wind tunnel tests.

\section{NOMENCLATURES}

$\begin{array}{ll}A O A & =\text { angle-of-attack } \\ C_{A} & =\text { axial force coefficient } \\ C_{N} & =\text { normal force coefficient } \\ C_{M} & =\text { pitching moment coefficient } \\ L / D & =\text { lift over drag ratio } \\ A M & =\text { additive manufacturing } \\ F D M & =\text { fused deposition modeling } \\ R P & =\text { rapid prototyping } \\ C F D & =\text { computational fluid dynamics } \\ N_{F} & =\text { normal force } \\ A_{F} & =\text { axial force }\end{array}$

\section{REFERENCES}

[1] Chiu, W.K., Yu, K.M. (2008). Direct digital manufacturing of 3 dimensional functionally graded material objects. Journal of Computer-Aided Design, vol. 40, no. 12, p. 1080-1093. DOI:10.1016/j. cad.2008.10.002.

[2] Pingyu, J., Fukuda, S. (2011). Tele RP- an internet web-based solution for remote rapid prototyping service and maintenance. International Journal of Computer Integrated Manufacturing, vol. 14, no. 1, p. 83-94, DOI:10.1080/09511920150214929.

[3] Landrum, D.B., Beard, R.M., LaSarge, P.A., Sprecken, N. (1997). Evaluation of stereolithography rapid prototyping for low speed airfoil design. $35^{\text {th }}$ Aerospace Sciences Meeting \& Exhibit.

[4] Aghanajafi, C., Daneshmand, S., Ahmadi Nadooshan, A. (2009). Investigation of surface roughness on aerodynamics properties. Journal of Aircraft, vol. 46, no. 3, p. 981-987, DOI:10.2514/1.39702.

[5] Springer, A., Cooper, K. (1998). Evaluating aerodynamic characteristics of wind-tunnel models produced by rapid prototyping methods. Journal of Spacecraft and rockets, vol. 35, no. 6, DOI: $10.2514 / 2.3412$.

[6] Hildebrand, R.J., Eidson, R.C., Tyler, C. (2003). Development of a low cost, rapid prototype lambda wing-body wind tunnel model. 21st Applied Aerodynamics Conference, AIAA, paper 3813.

[7] Tyler, C., Braisted, W., Higgins, J. (2005). Evaluation of rapid prototyping technologies for use in wind tunnel model fabrication. 43rd AIAA Aerospace Sciences Meeting \& Exhibit, AIAA, paper 1301.
[8] Nadooshan, A.A., Daneshmand, S., Aghanajafi, C. (2007). Application of RP technology with polycarbonate material for wind tunnel model fabrication. World Academy of Science, Engineering and Technology, vol. 32, no. 1, p. 1-6.

[9] Daneshmand, S., Adelnia, R., Aghanajafi, C. (2009). Design and production of wind tunnel testing models with FDM technology using ABSi. Journal Manufacturing Research, vol. 4, no. 2, p. 120-136, DOI:10.1504/IJMR.2009.024533.

[10] Daneshmand, S., Dehghani, A.R., Aghanajafi, C. (2007). Investigation of surface roughness on aerodynamics properties. Journal of Aircraft, vol. 44, no. 5, $p$. 1630-1634, DOI:10.2514/1.28030.

[11] Masood, S.H., Song, W.Q. (2004). Development of new metal/polymer materials for rapid tooling using fused deposition modelling. Materials and Design journal, vol. 25, no. 7, p. 587-594.

[12] Jacobs, P., (1995). Stereolithography and other RP\&M technologies from rapid prototyping to rapid tooling. American society of mechanical engineering.

[13] Tomislav, G., Milan, K., Mirko, K. (2008). Geometric accuracy by 2-D printing model. Strojniški vestnik Journal of Mechanical Engineering, vol. 54, no. 10, p. 725-733.

[14] Hopkinson, N., Hague, R.J.M., Dickens, P.M. (2006). Rapid manufacturing an industrial revolution for the digital age. John Wiley \& Sons Ltd., England, p. 7576, 235-237.

[15] Zein, I., Hutmacher, D.W., Tan, K.C., Teoh, S.H. (2002). Fused deposition modeling of novel scaffold architectures for tissue engineering applications. Biomaterials, vol. 23, no. 4, p. 1169-1185, DOI:10.1016/S0142-9612(01)00232-0.

[16] Noorani, R. (2006). Rapid prototyping principles and applications. John Wiley \& Sons, California, p. 181182.

[17] Daekeon, A., Kweon, J.H., Soonman, K., Jungil, S., Seokhee, L. (2009). Representation of surface roughness in fused deposition modeling. Journal of Materials Processing Technology, vol. 209, no. 16, p. 5593-5600, DOI:10.1016/j.jmatprotec.2009.05.016.

[18] Camplell, R.I., Mortorelli, M., Lee, H.S. (2002). Surface roughness visualization for rapid prototyping models. Computer Aided Design, vol. 34, no. 10, p. 717-725, DOI:10.1016/S0010-4485(01)00201-9.

[19] Springer, A. (1998). Evaluating aerodynamic characteristics of wind-tunnel models produced by rapid prototyping methods. Journal of Spacecraft and Rockets, vol. 35, no. 6, p. 755-759, DOI: $10.2514 / 2.3412$.

[20] Aghanajafi, C. (2000). Aeronomy. K. N. Toosi University of Technology Publication, Iran, p. 170-184. 